\title{
Porcine hemothropic mycoplasmas infection associated with productive impact in intensive pig production
}

Fernando Antônio Moreira Petri ${ }^{1}$, Karina Sonalio' ${ }^{1}$, Henrique Meiroz de Souza Almeida',

Maria Eugênia Silveira Ferraz² , Gabriel Yuri Storino ${ }^{1}$, Mauro Rodrigo de Souza ${ }^{3}$, Marcos Rogério André ${ }^{1}$ and Luis Guilherme de Oliveira ${ }^{*}$ (D)

\begin{abstract}
Background: So far, three porcine hemoplasmas (PH) have been identified, namely Mycoplasma suis, Mycoplasma parvum, and Mycoplasma haemosuis. The first one is the main agent associated with porcine hemoplasmosis, a possible cause of economic losses in pig production. Thus, this work aimed to detect and quantify PH 16S rRNA in finishing pigs and to associate its load estimate with average daily weight gain (ADWG). For this purpose, whole blood samples from 318 pigs were collected at an age of 75 days ( $(\mathrm{d} 0)$ when the pigs entered the finishing phase and 105 days later (d105). To calculate ADWG, the animals were weighed at the abovementioned dates. Then, DNA from blood samples were submitted to a $\mathrm{qPCR}$ targeting the $16 \mathrm{~S}$ rRNA gene for PH. Spearman correlation test was performed to investigate potential associations between ADWG and the quantification values. Lastly, the molecular characterization of PH was done by sequencing the $23 \mathrm{~S}$ rDNA gene.

Results: Out of the 318 samples, 190 (59.74\%) were positive on d0, and 304 (95.6\%) were positive on d105. A significant correlation was observed $(p<0.05)$, albeit with a low coefficient value $(0.18)$, when comparing ADWG with quantification values on d105. The phylogenetic analysis based on the $235 \mathrm{rDNA}$ gene showed that four sequences were closely related to M. parvum, and one sequence was positioned in the M. suis cluster.
\end{abstract}

Conclusion: Two PH, M. suis and M. parvum, were detected in a Brazilian pig farm. Moreover, increasing occurrence through time was observed, which may have affected the productive performance of positive animals, mainly at the end of the finishing phase, when antimicrobials are removed.

Keywords: ADWG, Intensive pig production, Mycoplasma parvum, Mycoplasma suis, aPCR

\section{Background}

Hemotropic mycoplasmas (HMs), also known as hemoplasmas, are commonly associated with infectious anemia in pigs [1]. So far, three hemoplasma species have been described infecting swine, namely M. suis, M. parvum, and M. haemosuis [2-4]. Mycoplasma suis is the main

\footnotetext{
* Correspondence: luis.guilherme@unesp.br

'São Paulo State University (Unesp), School of Agricultural and Veterinarian Sciences, Via de Acesso Prof. Paulo Donato Castellane s/n, Jaboticabal, São Paulo 14884-900, Brazil

Full list of author information is available at the end of the article
}

agent associated with the swine hemoplasmosis or eperythrozoonosis, which is caused by the pathogen's adherence to the RBCs surface, triggering the cell's death $[5,6]$. Also, swine hemoplasmosis has been pointed out as a possible cause of economic losses worldwide $[1,6,7]$. On the other hand, $M$. parvum infection has been associated with the absence of clinical signs, even at the peak of bacteremia [8]. Recently, M. haemosuis was detected in fattening pigs with skin lesions, fever, and anemia [9]. Even though the pathogenic potential of $M$. haemosuis, the more recently 
porcine hemoplasma described in China [4], Korea [10], and Germany [9], has not been fully investigated, clinical signs associated with it resemble those previously described for M. suis infections [7].

Porcine hemoplasmas $(\mathrm{PH})$ have been described in China [4, 11], the United States [12], Brazil [13-16, 17, 18], Germany [19, 20], France [21], South Korea [10], Japan [22, 23], Hungary [24], Switzerland [25], and Argentina [26]. Additionally, the first three countries, abovementioned, are amongst the four biggest pork producers in the world [27]. In general, PHs are small bacteria found attached to host's red blood cells, causing, in some cases, deformations to the cell structure and inducing eryptosis [28]. PH-infected swine can present the disease as acute and/or chronic manifestations. While the first is mostly associated with $M$. suis infection and characterized by severe anemia, jaundice, fever, gangrenous ear necrosis, enteritis, hypoglycemia and possible death, the chronic form of the disease seemns to be more common [7]. Moreover, $\mathrm{PH}$ infection in pigs may range from asymptomatic to growth retardation, poor reproductive performance, mild anemia, fever, skin lesions, and immunosuppression [3, 9, 27, 28].

Indeed, the chronic presentation of swine hemoplasmosis has been raised as a concern regarding production losses in the finishing phase of pig production, in which the most significant weight gain takes place [29]. Therefore, a reduction in productive and reproductive performance and the predisposition of $\mathrm{PH}$-infected pigs to secondary infections, may lead to financial losses in pig production [4]. Besides, it has been argued that pigs submitted to chronic challenges are prone to present a decrease in feed consumption and feed conversion rates [30]. However, to the best of authors' knowledge, these effects have not been assessed in hemoplasmas-infected pigs yet.

Even though PHs have been reported in the intensive $[18,31]$ and extensive $[15,17]$ pig production systems in Brazil, the influence of these agents on productive swine performance has not been assessed. Therefore, this body of work investigated the occurrence of $\mathrm{PH}$ and its association with average daily weight gain (ADWG) in finishing pigs from a commercial farm in Brazil.

\section{Results}

\section{PH occurrence and load estimate by qPCR}

All DNA samples amplified the predicted product for the mammals-gapdh gene. Out of the 318 samples, 190 (59.75\%) were positive for PHs by the qPCR assay on $\mathrm{d} 0$, and $304(95.60 \%)$ were positive on d105. The overall $\mathrm{PH}$ incidence was $93.75 \%(120 / 128)$. Among these positive animals, $58.6 \%$ were female $(75 / 174)$ and $35.15 \%$ male (45/136) pigs. Besides that, eight (2.52\%) animals were negative in both blood sampling, and only six (1.89\%) animals were positive on $\mathrm{d} 0$ and negative on $\mathrm{d} 105$.

Regarding the qPCR assays, all samples were run in duplicate, in 22 different plates, with reaction efficiencies (E) ranging from 92.2 to $102.7 \%$. The analytical assay sensitivity was $10^{1}$ numbers of PH $16 \mathrm{~S}$ rRNA copies $/ \mu \mathrm{L}$. The associated slope ranged from -3.526 to -3.259 , the determination coefficient $\left(R^{2}\right)$ values ranged from 0.987 to 0.998 , and the $y$-Int from 38.58 to 42.1 (Table S1). Cycle quantification values ranged from 19.17 to 39.94 on $\mathrm{d} 0$, and the SQ mean values ranged from $1.07 \times 10^{\circ}$ to $4.30 \times 10^{6} \mathrm{PH} 16 \mathrm{~S}$ rRNA copies $/ \mu \mathrm{L}$. Similarly, on d105, Cq values ranged from 15.82 to 39.38 , and SQ values ranged from $1.41 \times 10^{0}$ to $4.72 \times 10^{6}$ copies $/ \mu \mathrm{L}$ (Table S2). Curiously, a significant difference between SQ values from male and female pigs on $\mathrm{d} 0$ and $\mathrm{d} 105$ was observed (Table 1).

The samples in which an estimate of $\mathrm{PH}$ bacteremia was quantifiable $(n=108)$ were distributed into eight groups $\left(10^{0}\right.$ to $\left.10^{7}\right)$, according to SQ values (PH $16 \mathrm{~S}$ rDNA copies/ $\mu \mathrm{L}$ ) on $\mathrm{d} 0$ and $\mathrm{d} 105$ (Fig. 1). It was also noted that $68.5 \%(74 / 108)$ of the positive samples, for which an estimated bacteremia was quantifiable, showed increased SQ values during the finishing phase, whereas $31.48 \%(34 / 108)$ of these samples presented a decrease in the SQ values. Furthermore, $89(29.28 \%)$ out of the 304 positive samples showed inconsistent quantification results even after tested in triplicate (Table S2). This fact is most likely due to the Monte Carlo effect [31], which represents an inherent limitation of the technique, mainly in samples with a low number of porcine PH $16 \mathrm{~S}$ rDNA copies/ $\mu \mathrm{L}$. Even though PH $16 \mathrm{~S}$ rDNA could not be quantified in these samples, they were considered positive.

\section{Associations between PH 16S rDNA quantification and ADWG}

Regarding the ADWG according to the gender of sampled animals, males showed a mean of $0.95 \mathrm{~kg} /$ day $(\mathrm{SD}=$ 0.12 ; $\operatorname{Var}=0.015$ ) and females a mean of $0.88 \mathrm{~kg} /$ day $(\mathrm{SD}=0.12 ; \mathrm{Var}=0.011)$. The Wilcoxon test was performed to compare the ADWG and the pigs' gender, resulting in a significant difference between the means of ADWG of male and female pigs $\left(p=6.24 \times 10^{-9}\right)$. Besides this, the difference of SQ (d105 - d0) and ADWG mean was significant and positive on the Spearman correlation test (Rho $=0.142 ; p=0.011$ ) with low coefficient value, indicating that the two variables were weakly correlated. Still, no significant results were observed on the Spearman correlation test between ADWG and SQ mean of blood samples on d0 $(p=0.904)$. However, when comparing ADWG with SQ mean at d105, a significant correlation was observed $(p=0.001)$, but with low coefficient value (0.181) (Fig. 2; Table 2). 
Table 1 Starting quantity values (copies/ $\mu \mathrm{L}$ ) on d0 and d105 samples

\begin{tabular}{llllllll}
\hline & D0 samples & & & & \multicolumn{2}{l}{ D105 samples } & \\
\cline { 2 - 3 } \cline { 7 - 8 } & SQ mean & SD & Variance & & SQ mean & SD & Variance \\
\hline Male pigs & $5.82 \times 10^{4 \mathrm{a}}$ & $\pm 3.99 \times 10^{5}$ & $1.6 \times 10^{11}$ & & $2.35 \times 10^{5 \mathrm{~b}}$ & $\pm 1,12 \times 10^{6}$ & $7.61 \times 10^{10}$ \\
Female pigs & $7.21 \times 10^{3 \mathrm{a}}$ & $\pm 3.59 \times 10^{4}$ & $1.3 \times 10^{9}$ & & $8.16 \times 10^{4 \mathrm{~b}}$ & $\pm 2.76 \times 10^{5}$ & $1.26 \times 10^{12}$ \\
\hline
\end{tabular}

means followed by different superscript letters indicate significant difference $(p<0.05)$

\section{Molecular characterization of $\mathrm{PH}$}

BLASTn analysis for the obtained 23S rDNA sequences showed 91.10 to $99.88 \%$ identity with $M$. parvum strain Indiana (NR121958) and 90.10 to $96.54 \%$ identity with M. suis strain Illinois (NR103970), with query coverage ranging from 98 to 99 (Table 3).

Phylogenetic analysis of the five Mycoplasma spp. 23S rDNA sequences, estimated by the Bayesian method, showed that four 23S rDNA sequences were positioned close to $M$. parvum strain Indiana (NR121958) and only one (MT530439) was closely related to $M$. suis strain Illinois (NR103970) (Fig. 3). The numbers at the nodes correspond to bootstrap values accessed with 1.000.000 generations. Bacillus cereus and Bacillus subtilis were used as outgroup.

\section{Discussion}

Few studies have been conducted regarding the occurrence of $\mathrm{PH}$ and its economic impact on commercial pig farms in the world. This is the first report of $\mathrm{PH}$ detection by qPCR correlated to the average daily weight gain (ADWG) and its impact on finishing pigs from Brazil.

In the present work, $\mathrm{PH}$ was current in $59.75 \%$ of the animals at the beginning of the finishing phase, increasing its occurrence through time, reaching $95.60 \%$ at the end of this period (d105). Moreover, most animals (68.51\%) showed an increase in PH SQ values (copies/ $\mu \mathrm{L}$ ) from $\mathrm{d} 0$ to $\mathrm{d} 105$, while 120 animals (37.73\%) became positive after $\mathrm{d} 0$. These results agreed with previous studies, in which higher occurrence has been observed in older animals $[4,7,30]$. Accordingly, a study conducted in Germany [32] reported a PH occurrence of $31.25 \%$ in sows and $14.35 \%$ in piglets, suggesting that animals tend to become infected throughout the life. Even though the transmission of $\mathrm{PH}$ has been commonly associated with the infestation by the louse Haematopinus suis [33], its role in the transmission may have lower importance, since commercial pig farms are very technified and have adequate sanitary measures. As reported in the literature $[28,34]$, natural infections may be associated with fomites, like the reuse of needles and surgical instruments. Therefore, we believe that mechanical transmission by fomites and direct contact with infected blood, like cannibalism and fights, might have resulted in the transmission of $\mathrm{PH}$ between the sampled animals. Indeed, the mechanical transmission of $\mathrm{PH}$ may be a problem for the pig production in Brazil, since nearly all finishing animals usually originated from different herds, resulting in the introduction of positive animals and the dissemination of these agents.

Quantitative PCR results showed that more than $80 \%$ of the positive animals presented $\mathrm{PH}$ loads between $10^{-1}$ and $10^{4}$ copies $/ \mu \mathrm{L}$, corroborating previous studies conducted in Brazil $[15,17,18,31]$. PHs tend to establish chronic infections with nonclinical presentations in pigs $[6,35]$. According to our findings, most animals from this study might have presented a chronic infection characterized by low bacteremia and lack of clinical signs. This information could also explain the high occurrence of $\mathrm{PH}$ in Brazil once chronically infected
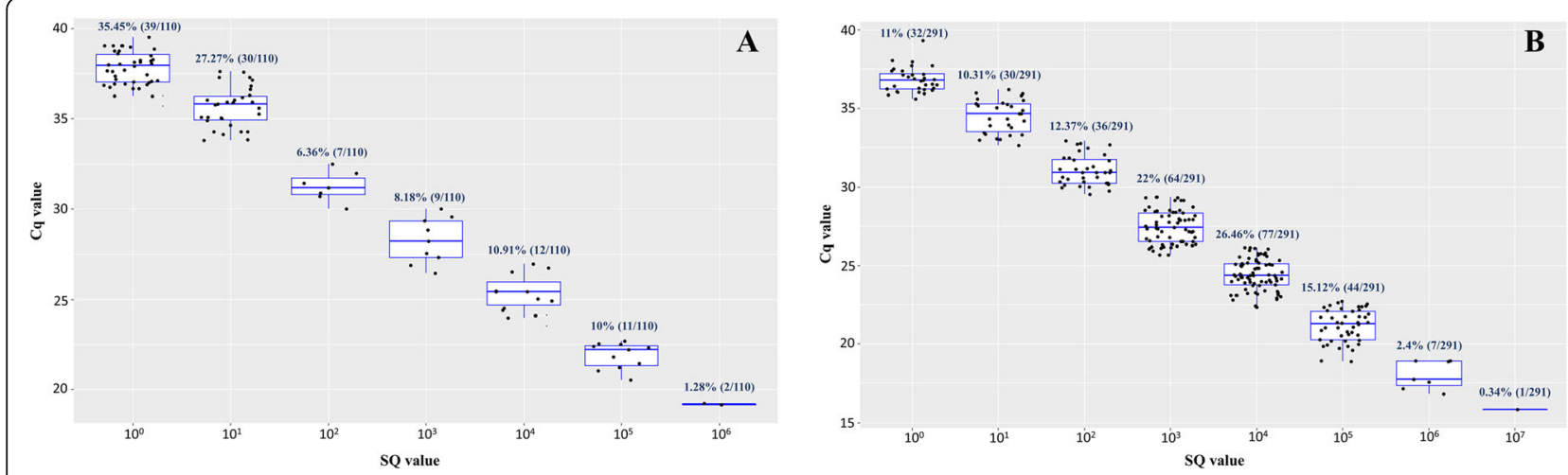

Fig. 1 Box plot showing the qPCR Cq results and distribution of SQ values. Quantification cycle (Cq) results and distribution of starting quantity (SQ) degree of dispersion by each sample in qPCR for PH-16S rRNA gene on d0 (a) and d105 (b) 


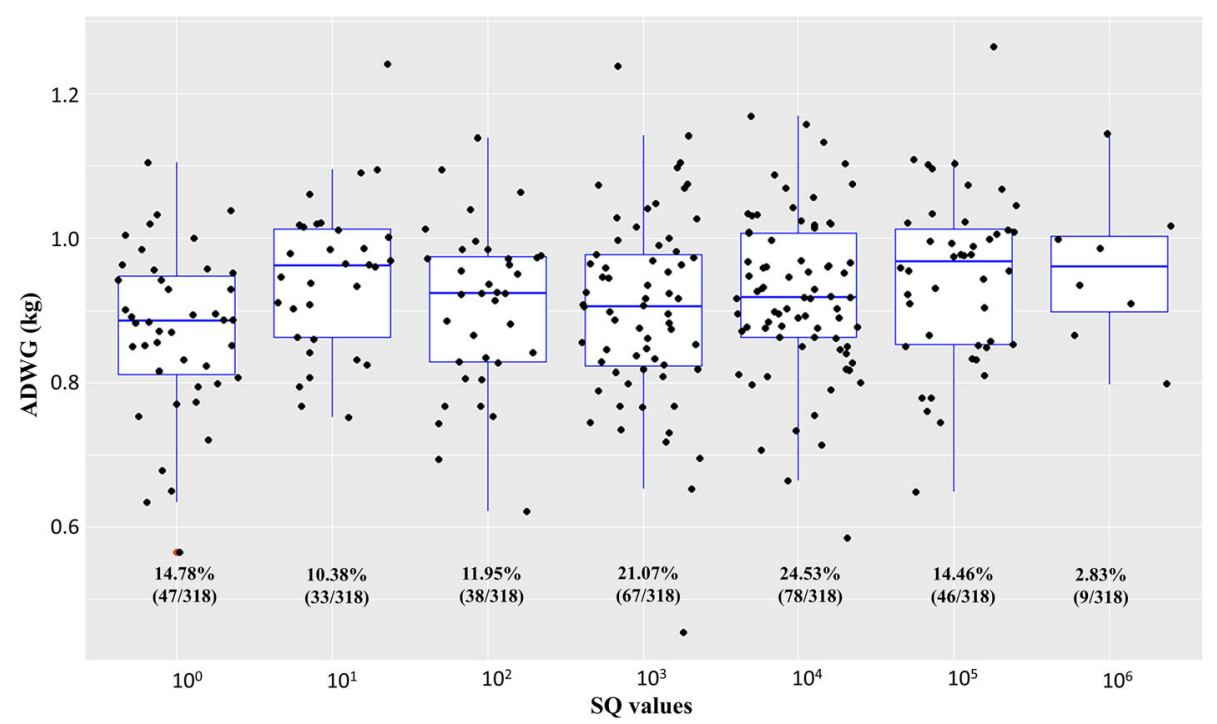

Fig. 2 Box plot showing the correlation between ADWG and SQ values on d105. Correlation of starting quantity (SQ) in samples of d105 and distribution of average daily weight gain (ADWG) degree of dispersion by each animal

animals play an essential role as a source of the infection. As observed previously, qPCR is very efficient at detecting extremely low bacterial loads and should be used as the standard test for $\mathrm{PH}$ detection worldwide. Besides, since conventional PCR and blood smears have demonstrated lower sensitivity and could result in falsenegative results, the occurrence of $\mathrm{PH}$ in pig farms could be underestimated $[12,20]$.

Regarding $\mathrm{PH}$ infection and its impact on pig production, our results showed that ADWG and bacteremia estimates were weakly correlated, indicating that there might be other pathogens associated with the decrease of ADWG in the evaluated animals. An example could be the respiratory disease caused by Mycoplasma hyopneumoniae [36], which has been commonly associated with a decrease in productivity. Furthermore, ADWG of PHinfected male pigs was higher than ADWG from female pigs $(0.95 \mathrm{~kg} /$ day and $0.88 \mathrm{~kg} /$ day, respectively). This could be associated with the body composition, which is quite different between genders, where entire males are more efficient in feed conversion than females [37]. Similarly,

Table 2 Potential correlations between ADWG and SQ values on d0 and d105

\begin{tabular}{lll}
\hline Variables & Coefficient & $P$-value \\
\hline $\mathrm{SQ}_{\mathbf{1}} \times \mathrm{SQ}_{\mathbf{2}}$ & 0.08 & 0.05 \\
$\mathrm{SQ}_{\mathrm{m}} \times \mathrm{ADWG}$ & 0.14 & 0.01 \\
$\mathrm{SQ}_{1} \times$ ADWG & 0.007 & $0.94^{*}$ \\
$\mathrm{SQ}_{\mathbf{2}} \times \mathrm{ADWG}$ & 0.18 & 0.001 \\
\hline
\end{tabular}

$S Q_{1}$ Starting quantification value on $d 0, S Q_{2}$ Starting quantification value on d105, $S Q_{m}$ Starting quantification mean

*There was no correlation when the productive performance of immunologically castrated boars, physically castrated males, entire males, and entire female pigs were compared, the results indicated that immunologically castrated boars were more efficient in feed conversion [38]. Therefore, in this study, the sampled males were previously immune castrated, and so, a higher ADWG was expected compared to the female pigs.

Similarly, to the average daily weight gain, bacteremia estimate levels were higher in male pigs than those found among female pigs in both analyzed phases (75 and 190 days of life). However, we should consider that nearly $90 \%$ of the positive animals showed SQ values lower than $10^{4}$ copies $/ \mu \mathrm{L}$, indicating that these pigs were chronically infected and did not show severe signs of anemia [18]. Besides, it is likely possible that $M$. parvum is the primary pathogen associated with $\mathrm{PH}$ in Brazil, and this $\mathrm{PH}$ does not cause any clinical signs, even at the peak of the bacteremia, and yet, seems to persist at low levels in the blood [8]. On the other hand, when comparing ADWG with SQ mean on d105, a significant correlation was observed. This fact may be associated with the withdrawal of antimicrobials 15 days before slaughter, aiming at avoiding the presence of residues in the meat. Besides, antimicrobials as metaphylaxis may also control $\mathrm{PH}$ infection and its productive impact on the finishing phase, allowing a higher multiplication only after its complete withdrawal. Considering that antimicrobial use in pig production is a big concern, many countries have prohibited its use as growth promoters and disease prevention. Therefore, it is possible that diseases inhibited by antimicrobials' preventive use may emerge and become a serious problem in pig production worldwide. 
Table 3 BLASTn information on the five $23 \mathrm{~S}$ rDNA sequences obtained from this study

\begin{tabular}{|c|c|c|c|c|c|}
\hline \multirow{2}{*}{$\begin{array}{l}\text { Sample } \\
\text { ID }\end{array}$} & \multirow{2}{*}{$\begin{array}{l}\text { Collection } \\
\text { Time }\end{array}$} & \multirow{2}{*}{$\begin{array}{l}\text { Accession } \\
\text { Number }\end{array}$} & \multicolumn{2}{|l|}{ Identity \% } & \multirow{2}{*}{$\begin{array}{l}\text { Query } \\
\text { Cover } \\
\%\end{array}$} \\
\hline & & & M. parvum strain Indiana NR121958.1 & M. suis strain Illinois NR103970.1 & \\
\hline \multirow[t]{2}{*}{36} & d0 & MT 530438 & 99.65 & 90.21 & 99 \\
\hline & d105 & MT 530441 & 99.88 & 90.39 & 98 \\
\hline 43 & do & MT 530439 & 91.10 & 96.54 & 99 \\
\hline \multirow[t]{2}{*}{104} & do & MT 530440 & 99.65 & 90.18 & 98 \\
\hline & d105 & MT 530442 & 99.53 & 90.10 & 99 \\
\hline
\end{tabular}

The phylogenetic tree based on the 23S rDNA gene of hemoplasmas showed the occurrence of both $M$. suis and $M$. parvum in the studied herd. The concomitant presence of both $\mathrm{PH}$ has been previously reported in sows from southern Brazil [30]. When comparing M. suis strain Illinois to $M$. parvum strain Indiana, bacteremia levels, at the peak, were one log lower for $M$. parvum than M. suis [8]. Additionally, these two pathogens are genetically related, and the genome of $M$. parvum has orthologous for all the protein-coding sequences (CDS) with metabolic functions identified in the genome of $M$. suis [8]. Still, a set of unique paralogous CDS of $M$. suis have a higher percentage of signal peptides detected than $M$. parvum CDS, which could play an important role in the pathogenicity of the first $[8,12]$. Considering the high degree of genetic similarity between $M$. suis and M. parvum, it is crucial to use less conserved gene fragments, e.g. $23 \mathrm{~S}$ rDNA, to assess the phylogenetic positioning of these agents, and thus, get a better picture of $\mathrm{PH}$ occurrence in swine herds worldwide.

\section{Conclusion}

Porcine hemoplasmas occurrence increased through the finishing phase, showing an inverse correlation between PH 16S rDNA quantification values at d105 and average daily weight gain. Besides, the occurrence of two porcine hemoplasmas in the same herd, namely $M$. suis and $M$. parvum, was reported, indicating possible coinfection.

\section{Methods}

\section{Study design and sampling}

The study was carried out from November 2018 through March 2019 in a pig production farm belonging to an integration system, located in Patos de Minas $\left(18.5873^{\circ} \mathrm{S}\right.$, $\left.46.5147^{\circ} \mathrm{W}\right)$, Minas Gerais State, southeastern Brazil. It was conducted with the approval of the School of Agricultural and Veterinarian Sciences' Animals Ethics Committee (CEUA) under permit number 073778/19. Appropriate permission was obtained from the farm owners before collection of blood samples from the animals.

In total, 318 pigs (male and female) from the same batch were selected at the beginning of the rearing/finishing phase, approximately 75 days of age (d0). The selected pigs were identified with ear tags with random numbering and weighed at the beginning and at the end of the finishing phase (d105), to determine the average daily weight gain (ADWG). The animals were slaughtered at 180 days of life (d105), and for each animal included in the assay, a whole blood sample was collected in Vacutest $\mathrm{V}^{\oplus}$ tubes, containing ethylenediaminetetraacetic acid (EDTA). Blood collection was carried out on two occasions: first, at the beginning of the finishing phase

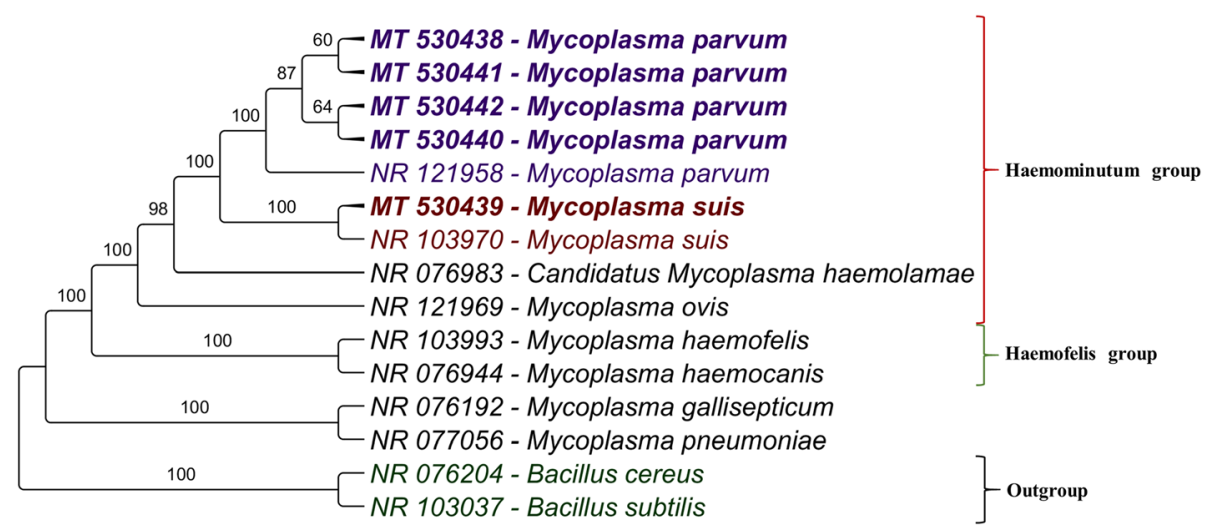

Fig. 3 Phylogenetic tree based on Mycoplasma spp. 23S rRNA sequences. Phylogenetic analysis based on the Bayesian method, and the TrN + G evolutionary model. Accession numbers are indicated in the sequences. Porcine hemoplasmas sequences detected in the present study are highlighted in bold. Numbers at the nodes correspond to bootstrap 
(d0) and, second, at the end of this phase, in a slaughterhouse (d105). The animals have no obvious clinical symptoms during blood sampling. After sampling, the blood samples were aliquoted in cryogenic tubes, conditioned in liquid nitrogen and transported to the Swine Medicine Laboratory, in the Department of Veterinary Clinic of the Faculty of Agricultural and Veterinary Sciences (FCAV- UNESP), campus of Jaboticabal, where they were stored at $-80{ }^{\circ} \mathrm{C}$ until processing.

\section{DNA extraction and conventional (c) PCR for the mammals-gapdh gene}

DNA extraction was performed as previously described protocol [39]. To rule out the presence of inhibitors in the extracted DNA samples and the occurrence of false negative in the qPCR for PHs, all samples were submitted to a conventional PCR (cPCR) using the gapdh-F primer oligonucleotides (5'-CCTTCATTGACCTCAA CTACAT-3') and gapdh-R (5'-CCAAAGTTGT CATGGATGACC3'), which flank a fragment of the mammals-gapdh gene [40]. The amplified products were subjected to horizontal electrophoresis on 1\% agarose gels stained with Ethidium Bromide $(1 \mu \mathrm{L} / 20 \mathrm{~mL}$ ) (Life Technologies $^{\mathrm{TM}}$, Carlsbad, California, USA) in TBE pH 8.0 running buffer at a current of $90 \mathrm{~V} / 50 \mathrm{~mA}$ for $50 \mathrm{~min}$. Then, the amplified products were visualized using an ultraviolet light transilluminator (Chemi-Doc, Bio-Rad ${ }^{\circledR}$ ).

\section{Porcine hemoplasmas-qPCR based on the 16S rRNA gene} DNA samples positive in the CPCR for the endogenous mammals-gadph gene were subjected to a qPCR assay based on the $16 \mathrm{~S}$ rDNA coding gene for $\mathrm{PH}$, using the primer oligonucleotides (Integrated DNA Technologies, Coralville, Iowa, USA) F (5' - CCCTGATTGTACTAATTGAATAAG$3^{\prime}$ ) and R (5'-GCGAACACTTGT-TAAGCAAG-3') and the TaqMan hydrolysis probe (5'FAM- TGRATACACA YTTCAG-MGBNFQ3' [12]. The amplification reaction was performed according to the protocol described in the literature [12], completed in a CFX 96 Thermocycler (BioRad $\left.{ }^{\oplus}\right)$.

Ten-fold serial dilutions were performed, from $10^{7}$ copies/ $\mu \mathrm{L}$ until $10^{1}$ copies $/ \mu \mathrm{L}$, to determine the different concentrations of IDT SMART plasmids (Integrated DNA Technologies, Coralville, Iowa, USA) containing the target sequence. In all qPCR assays, plasmids and sterile ultrapure water were used as positive and negative control, respectively (Nuclease-Free Water, Promega ${ }^{\oplus}$, Madison, United States).

CPCR for Mycoplasma spp. based on the 23S rRNA gene

To amplify a $800 \mathrm{pb}$ fragment of Mycoplasma spp. 23S rRNA gene fragment, a cPCR assay, was performed using the primers 23S_HAEMO_F (5' - TGAGGGAAAG AGCCCAGAC-3') and 23S_HAEMO_R (5-'-GGACAG AATTTACCTGACAAGG-3'), described by Mongruel et al. (unpublished). The amplification reaction contained 1x PCR buffer, $1.5 \mathrm{mM}$ of $\mathrm{MgCl}_{2}, 0.2 \mathrm{mM}$ of each dNTP, $0.4 \mathrm{mM}$ of each primer, $2.5 \mathrm{U}$ of Taq Platinum DNA Polymerase (Life Technologies ${ }^{\mathrm{Tm}}$, California, USA), $5 \mu \mathrm{L}$ of DNA template, and ultra-pure water q.s.p $25 \mu \mathrm{L}$. The cycling conditions consisted of $3 \mathrm{~min}$ denaturation at $94{ }^{\circ} \mathrm{C}$ followed by 35 cycles of $94{ }^{\circ} \mathrm{C}$ for $30 \mathrm{~s}, 54{ }^{\circ} \mathrm{C}$ for $30 \mathrm{~s}$ and $72{ }^{\circ} \mathrm{C}$ for $60 \mathrm{~s}$, with a final extension of $72^{\circ} \mathrm{C}$ for $10 \mathrm{~min}$. The amplified product was visualized in $1 \%$ agarose gel as above described on the cPCR for the gapdh gene section.

\section{Sequencing and sequence analyses}

Amplified products were purified using the "Exosap IT" kit (Applied Biosystems, Cleveland, Ohio, USA) according to the manufacturer's recommendations. The sequencing of amplified products was performed according to the method described in existent literature [41]. The resulting sequences were then submitted to a screening test using Phred-Phrap software version 23 $[42,43]$ to check for the chromatogram quality. BLAST program [44] was used to analyze the nucleotides' sequence and to search for the percentage of identity with previously deposited sequences in GenBank [45].

\section{Phylogenetic analyses}

The 23S rRNA sequences originated from this study, and those retrieved from GenBank were aligned using MAFFT software [46]. The Bayesian inference (BI) analysis was performed with MrBayes 3.1.2 [47] via CIPRES Science Gateway [48]. The best evolutionary model was selected by the program jModelTest2 (version 2.1.6) on XSEDE [49], under the Akaike Information Criterion (AIC) [50]. The tree was edited in TreeGraph $2.0 \beta$ [51]. The bootstrapping values were indicated at the nodes, based on 1.000.000 generations. The number of generations was selected based on the value of the average standard deviation of split frequencies (between 0.01 and 0.05) according to MrBayes version 3.2 Manual [47].

\section{Data analysis}

To detect potential correlations between $\mathrm{PH}$ prevalence and continuous variables, data normality was assessed using the Shapiro-Wilkins test $(p<0.05)$. While the Pearson correlation coefficient $(p<0.05)$ was used to detect significant correlations if the data presented normal distribution, Spearman's rank coefficient test $(p<0.05)$ was used for non-parametric data. To compare the ADWG and the pigs' gender, the Wilcoxon test was performed. The abovementioned analysis was performed using the software $\mathrm{R}$ version 3.5.1 [52]. Moreover, to find the $\mathrm{PH}$ incidence value, the number of new cases between $\mathrm{d} 0$ and $\mathrm{d} 105$ was divided by the number of negative animals from the first blood sampling. 


\section{Supplementary information}

The online version contains supplementary material available at https://doi. org/10.1186/s40813-020-00171-1.

Additional file 1: Table S1. Parameters of qPCR assays based on 16S rRNA gene from pigs on d0 and d105. Table S2. Detailed information on qPCR results of the 318 samples at d0 and d105. (DOCX $112 \mathrm{~kb}$ )

\section{Abbreviations}

16S rDNA: 16S ribosomal DNA; 165 rRNA: 165 ribosomal RNA; ADWG: Average daily weight gain; CDS: Protein-coding sequences; CPCR: Conventional polymerase chain reaction; Cq: Quantification cycle; DNA: Deoxyribonucleic acid; EDTA: Ethylenediaminetetraacetic acid; HM: Hemothropic mycoplasma; M. haemosuis: Mycoplasma haemosuis; M. parvum: Mycoplasma parvum; M. suis: Mycoplasma suis; PH: Porcine hemoplasmas; qPCR: Quantitative real time polymerase chain reaction; SQ: Starting quantification; TBE: Tris-borate-EDTA

\section{Acknowledgments}

The authors wish to thank the colleagues from the Swine Medicine Laboratory and the team of Immunoparasitology Laboratory for whole assistance during the conduction of this work.

\section{Authors' contributions}

Study design: LGO, KS, FAMP. Sampling: KS, GYS, HMSA, MESF, MRS Laboratory analysis: KS, FAMP. Data analysis: KS, HMSA. Interpretation of data: KS, FAMP, HMSA, LGO, MRA. Writing the manuscript: KS, MRA, FAMP, HMSA, MESF, GYS, LGO, MRS. All authors read, reviewed, and approved the final manuscript.

\section{Funding}

We are thankful to the São Paulo Research Foundation (FAPESP) for the scientific initiation scholarship to Fernando A. M. Petri (Process No. 2019/ 14122-7) and Ceva Animal Health Brazil for funding part of the study. We are also thankful to CNPq for the Productivity Grant granted to the MRA (CNPq Process No. 302420/2017-7).

\section{Availability of data and materials}

The $M$. suis and M. parvum partial genome sequence obtained in this study had been uploaded to GenBank. The datasets used and/or analysed during the current study are available from the corresponding author on reasonable request.

\section{Ethics approval and consent to participate}

This project was submitted to the School of Agricultural and Veterinarian Sciences' Ethics Commission for Animal Experimentation (CEUA) and approved under permit number $073778 / 19$. During the entire experiment, all animals received humane care in compliance with good animal practice to minimize animal sufferings during blood sampling, according to the anima ethics procedures and guidelines in Brazil.

\section{Consent for publication}

All authors gave their consent for publication.

\section{Competing interests}

The authors declare that they have no competing interests.

\section{Author details}

'São Paulo State University (Unesp), School of Agricultural and Veterinarian Sciences, Via de Acesso Prof. Paulo Donato Castellane s/n, Jaboticabal, São Paulo 14884-900, Brazil. ²Evance Animal Health, João Baptista de Queiroz Júnior, 447, Campinas, São Paulo 13098-415, Brazil. ${ }^{3}$ Ceva Animal Health, Manoel Joaquim Filho, 303, Paulínia, São Paulo, Brazil.
Received: 15 July 2020 Accepted: 9 October 2020

Published online: 04 November 2020

\section{References}

1. Hoelzle LE. Haemotrophic mycoplasmas: recent advances in Mycoplasma suis. Vet Microbiol. 2008;130(3-4):215-26. https://doi.org/10.1016/j.vetmic. 2007.12.023.

2. Kinsley AT. Protozoan-like body in the blood of swine. Vet Med Int. 1932;27: 196.

3. Splitter EJ. Eperythrozoon suis n. sp. and Eperythrozoon parvum n. sp., 2 new blood parasites of swine. Science. 1950;111:513-4. https://doi.org/10.1126/ science.111.2889.513

4. Fu Y, Shi T, Xu L, Wei W, Lu F, et al. Identification of a novel Hemoplasma species from pigs in Zhejiang province, China. J Vet Med Sci. 2017;79:86470. https://doi.org/10.1292/jvms.16-0545.

5. Hoelzle LE, Zeder M, Felder KM, Hoelzle K. Pathobiology of mycoplasma suis. Vet J. 2014;202:20-5.

6. Groebel K, Hoelzle K, Wittenbrink MM, Ziegler U, Hoelzle LE. Mycoplasma suis invades porcine erythrocytes. Infect Immun. 2009;77(2):576-84. https:// doi.org/10.1128/IAl.00773-08.

7. Stadler J, Jannasch C, Mack SL, Dietz S, Zöls S, Ritzmann M, Hoelzle K, Hoelzle LE. Clinical and haematological characterisation of Mycoplasma suis infections in splenectomised and non-splenectomised pigs. Vet Microbiol. 2014:172:294-300. https://doi.org/10.1016/j.vetmic.2014.05.012.

8. Do Nascimento NC, Dos Santos AP, Chu Y, Guimaraes AM, Baird AN, Weil AB, Messick JB. Microscopy and genomic analysis of Mycoplasma parvum strain Indiana. BMC Vet Res. 2014;45(86):1-11. https://doi.org/10.1186/ s13567-014-0086-7.

9. Stadler J, Ade J, Ritzmann M, Hoelzle K, Hoelzle LE. Detection of a novel haemoplasma species in fattening pigs with skin alterations, fever and anaemia. Vet Record. 2020. https://doi.org/10.1136/vr.105721.

10. Seo MG, Kwon OD, Kwak D. Prevalence and phylogenetic analysis of hemoplasma species in domestic pigs in Korea. Parasit Vectors. 2019;12(1): 378. https://doi.org/10.1186/s13071-019-3638-x Published 2019 Jul 29.

11. Song Q, Zhang W, Song W, Liu Z, et al. Seroprevalence and risk factors of Mycoplasma suis infection in pig farms in Central China. Prev Vet Med. 2014; 117:215-21. https://doi.org/10.1016/j.prevetmed.2014.07.006.

12. Guimaraes $A M$, Vieira RF, Poletto $R$, Vemulapalli AP, et al. A quantitative TaqMan PCR assay for the detection of Mycoplasma suis. J Appl Microbiol. 2011;111(2):417-25. https://doi.org/10.1111/j.1365-2672.2011.05053.x.

13. Guimaraes AM, Biondo AW, Lara AC, Messick JB. Exploratory study of Mycoplasma suis (Eperythrozoon suis) on four commercial pig farms in southern Brazil. Vet Rec. 2007;160(2):50-3. https://doi.org/10.1136/vr.160.2.50

14. Dias GB, do Amaral RB, IRH G, Lapera IM, de Oliveira LG, Lux-Hoppe EG, Machado RZ, André MR. Molecular detection of Mycoplasma suis in captive white-lipped peccaries (Tayassu pecari) and wild boars (Sus scrofa) in Brazil. Comp Immunol Microbiol Infect Dis. 2019;63:94-6. https://doi.org/10.1016/j. cimid.2019.01.013

15. Martins MSDS, Silva LD, Miranda LM, Lima CAA, et al. Molecular detection of Mycoplasma suis in extensive pig production systems in the State of Maranhão, northeast Brazil. Rev Bras Parasitol Vet. 2019;28(2):306-9. https:// doi.org/10.1590/S1984-296120180099.

16. Sonalio K, Perles L, Gatto IRH, do Amaral RB, Almeida HMS, Galdeano JVB, Vieira RFC, André MR, de Oliveira LG. Genetic diversity of emerging hemotropic mycoplasmas in domestic pigs from Brazil. Transbound Emerg Dis. 2020. https://doi.org/10.1111/tbed.13767.

17. Toledo MA, Leite Al, Gonçalves LR, Sousa KCM, et al. High occurrence of Mycoplasma suis infection in swine herds from non-technified farms in Mossoró, state of Rio Grande do Norte, Northeastern Brazil. Rev Bras Parasitol Vet. 2016;25(4):414-7. https://doi.org/10.1590/S1984-29612016084.

18. Ritzmann M, Grimm J, Heinritzi K, Hoelzle K, Hoelzle LE. Prevalence of Mycoplasma suis in slaughter pigs, with correlation of $P C R$ results to hematological findings. Vet Microbiol. 2009;133:84-91. https://doi.org/10. 1016/j.vetmic.2008.06.015.

19. Hoelzle K, Engels M, Kramer MM, Wittenbrink MM, Dieckmann SM, Hoelzle LE. Occurrence of Mycoplasma suis in wild boars (Sus scrofa L.). Vet Microbiol. 2010;143:405-9. https://doi.org/10.1016/j.vetmic.2009.11.015.

20. Normand V Boulbria G, Brissonnier M, Bachy V Moalic PY, Berton P, Bouchet F, Lebret A. Comparison of qPCR and blood smear microscopy for the diagnosis of Mycoplasma suis in a French veterinary practice. Porcine Health Manag. 2020;6:4-7. https://doi.org/10.1186/s40813-019-0143-8. 
21. Watanabe $Y$, Fujihara M, Obara H, Nagai K, Harasawa R. Two genetic clusters in swine hemoplasmas revealed by analyses of the 16s rRNA and RNase P RNA genes. J Vet Med Sci. 2011;73:1657-61. https://doi.org/10.1292/jvms.11-0293.

22. Watanabe Y, Fujihara M, Suzuki J, Sasaoka F, Nagai K, Harasawa R. Prevalence of swine hemoplasmas revealed by real-time PCR using 165 rRNA gene primers. J Vet Med Sci. 2012;74(10):1315-8. https://doi.org/10.1292/jvms.12-0096.

23. Hornok S, Sugár L, Fernández de Mera IG, de la Fuente J, et al. Tick- and flyborne bacteria in ungulates: the prevalence of Anaplasma phagocytophilum, haemoplasmas and rickettsiae in water buffalo and deer species in Central Europe, Hungary. BMC Vet Res. 2018;14(1):98. https://doi.org/10.1186/ s12917-018-1403-6 Published 2018 Mar 20.

24. Hoelzle LE, Helbling M, Hoelzle K, Ritzmann M, Heinritzi K, Wittenbrink MM First LightCycler real-time PCR assay for the quantitative detection of Mycoplasma suis in clinical samples. J Microbiol Methods. 2007;70:346-54. https://doi.org/10.1016/j.mimet.2007.05.009.

25. Pereyra NB, Perez AM, Messick JB, Cane FD, Guglielmone AA. Estimación de la sensibilidad y especificidad de dos pruebas diagnósticas para la detección de Mycoplasma suis en Argentina utilizando un modelo bayesiano. Arch Med Vet. 2011;43:117-25. https://doi.org/10.4067/S0301732X2011000200004

26. USDA, United States Department of Agriculture. Livestock and poultry. United States of America: World Markets and Trade; 2020. Available online at::

27. Felder KM, Hoelzle K, Ritzmann M, Kilchling T, Schiele D, Heinritzi K, Groebel $\mathrm{K}$, Hoelzle LE. Hemotrophic mycoplasmas induce programmed cell death in red blood cells. Cell Physiol Biochem. 2011;27:557-64. https://doi.org/10. 1159/000329957.

28. Henry SC. Clinical observations on eperythrozoonosis. J Am Vet Med Assoc. 1979;174:601-3.

29. Pastorelli H, Van Milgen J, Lovatto P, Montagne L. Meta-analysis of feed intake and growth responses of growing pigs after a sanitary challenge. Animal. 2012;6:952-61. https://doi.org/10.1017/S175173111100228X

30. Gatto IRH, Sonálio K, Amaral RB, Morés N, Dalla Costa OA, André MR, de Oliveira LG. High frequency and molecular characterization of porcine hemotrophic mycoplasmas in Brazil. Vet Microbiol. 2019;231:33-9. https:// doi.org/10.1016/j.vetmic.2019.02.024

31. Bustin SA, Benes V, Garson JA, et al. The MIQE guidelines: minimum information for publication of quantitative real-time PCR experiments. Clin Chem. 2009;55:611-22. https://doi.org/10.1373/clinchem.2008.112797.

32. Stadler J, Willi S, Ritzmann M, Eddicks M, et al. Detection of Mycoplasma suis in pre-suckling piglets indicates a vertical transmission. BMC Vet Res. 2019; 15(1):252. https://doi.org/10.1186/s12917-019-2001-y Published 2019 Jul 19.

33. Heinritzi K, Plank G. Einfluss der Eperythrozoon-suis-Infektion auf die osmotische Resistenz der Erythrozyten [The effect of Eperythrozoon suis infection on the osmotic fragility of erythrocytes]. Berl Munch Tierarztl Wochenschr. 1992;105(11):380-3.

34. Yuan CL, Liang AB, Yao CB, et al. Prevalence of Mycoplasma suis (Eperythrozoon suis) infection in swine and swine-farm workers in Shanghai, China. Am J Vet Res. 2009;70:890-4. https://doi.org/10.2460/ajvr.70.7.890.

35. Messick JB. Hemotrophic mycoplasmas (hemoplasmas): a review and new insights into pathogenic potential. Vet Clin Pathol. 2004;33:2-13. https://doi. org/10.1111/j.1939-165X.2004.tb00342.x.

36. Ferraz M, Almeida H, Storino GY, Sonálio K, Souza MR, Moura C, Costa W, Lunardi L, Linhares D, de Oliveira LG. Lung consolidation caused by Mycoplasma hyopneumoniae has a negative effect on productive performance and economic revenue in finishing pigs. Prev Vet Med. 2020; 182:105091. https://doi.org/10.1016/j.prevetmed.2020.105091.

37. Gispert M, Angels Oliver M, Velarde A, Suarez P, Pérez J, Font i Furnols M. Carcass and meat quality characteristics of immunocastrated male, surgically castrated male, entire male and female pigs. Meat Sci. 2010;85(4):664-70. https://doi.org/10.1016/j.meatsci.2010.03.021

38. Morales J, Gispert M, Hortos M, Pérez J, Suárez P, Piñeiro C. Evaluation of production performance and carcass quality characteristics of boars immunised against gonadotropin-releasing hormone $(\mathrm{GnRH})$ compared with physically castrated male, entire male and female pigs. Span J Agric Res. 2010;8:599-606. https://doi.org/10.5424/sjar/2010083-1255.

39. Kuramae-lzioka EE. A rapid, easy and high yield protocol for total genomic DNA isolation of Colletotrichum gloeosporioides and Fusarium oxysporum. Rev Univ Estadual Mar. 1997;19:683-9.

40. Birkenheuer AJ, Levy MG, Breitschwerdt EB. Development and evaluation of a seminested PCR for detection and differentiation of Babesia gibsoni (Asian genotype) and B. canis DNA in canine blood samples. J Clin Microbiol. 2003; 41(9):4172-7. https://doi.org/10.1128/jcm.41.9.4172-4177.2003.

41. Sanger F, Nicklen S, Coulson AR. DNA sequencing with chain-terminating inhibitors. Proc Natl Acad Sci U S A. 1977;74(12):5463-7. https://doi.org/10. 1073/pnas.74.12.5463.

42. Ewing B, Green P. Base-calling of automated sequencer traces using phred. II Error probabilities. Genome Res. 1998:8(3):186-94.

43. Ewing B, Hillier L, Wendl MC, Green P. Base-calling of automated sequencer traces using phred. I. Accuracy assessment. Genome Res. 1998;8(3):175-85. https://doi.org/10.1101/gr.8.3.175

44. Altschul SF, Gish W, Miller W, Myers EW, Lipman DJ. Basic local alignment search tool. J Mol Biol. 1990;215(3):403-10. https://doi.org/10.1016/S00222836(05)80360-2.

45. Benson DA, Cavanaugh M, Clark K, Karsch-Mizrachi I, et al. GenBank. Nucleic Acids Res. 2013:41(Database issue):D36-42. https://doi.org/10.1093/nar/ gks1195.

46. Katoh K, Rozewicki J, Yamada KD. MAFFT online service: multiple sequence alignment, interactive sequence choice and visualization. Brief Bioinform. 2018;20:1160-6. https://doi.org/10.1093/bib/bbx108.

47. Ronquist F, Huelsenbeck JP. MrBayes 3: Bayesian phylogenetic inference under mixed models. Bioinformatics. 2003;19:1572-4. https://doi.org/10. 1093/bioinformatics/btg180.

48. Miller MA, Pfeiffer W, Schwartz T. Creating the CIPRES Science Gateway for inference of large phylogenetic trees, 2010. New Orleans: Gateway Computing Environments Workshop (GCE), 2010. https://doi.org/10.1109/ GCE.2010.56761.

49. Darriba D, Taboada GL, Doallo R, Posada D. JModelTest 2: more models, new heuristics and parallel computing. Nat Methods. 2012;9:772. https://doi. org/10.1038/nmeth.2109.

50. Posada D, Buckley TR. Model selection and model averaging in phylogenetics: advantages of akaike information criterion and bayesian approaches over likelihood ratio tests. Syst Biol. 2004;53:793-808. https://doi. org/10.1080/10635150490522304.

51. Stöver BC, Müller KF. TreeGraph 2: combining and visualizing evidence from different phylogenetic analyses. BMC Bioinformatics. 2010;11:7. https://doi. org/10.1186/1471-2105-11-7 Published 2010 Jan 5.

52. R Core Team. R: a language and environment for statistical computing. Vienna: R Foundation for Statistical Computing; 2018.

\section{Publisher's Note}

Springer Nature remains neutral with regard to jurisdictional claims in published maps and institutional affiliations.

Ready to submit your research? Choose BMC and benefit from:

- fast, convenient online submission

- thorough peer review by experienced researchers in your field

- rapid publication on acceptance

- support for research data, including large and complex data types

- gold Open Access which fosters wider collaboration and increased citations

- maximum visibility for your research: over $100 \mathrm{M}$ website views per year

At BMC, research is always in progress.

Learn more biomedcentral.com/submissions 